\title{
Molecular characteristics of breast cancer according to clinicopathological factors
}

\author{
JOANNA HUSZNO $^{1}$ and ZOFIA KOLOSZA ${ }^{2}$ \\ ${ }^{1}$ I Radiation and Clinical Oncology Department; ${ }^{2}$ Biostatistic Unit, \\ Maria Skłodowska-Curie Memorial Cancer Center and Institute of Oncology, 44-101 Gliwice, Poland
}

Received August 27, 2018; Accepted April 11, 2019

DOI: $10.3892 / \mathrm{mco} .2019 .1869$

\begin{abstract}
The purpose of the present study was to evaluate the correlation between molecular factors such as BRCA1 DNA repair associated (BRCA1), checkpoint kinase 2 (CHEK2) and nucleotide binding oligomerization domain containing 2 (NOD2) gene mutations and clinicopathological factors in patients with breast cancer (BC). Prognostic factors were analyzed in BC patients with confirmed BRCAl $(\mathrm{n}=73)$, CHEK2 $(\mathrm{n}=51)$ and NOD2 $(\mathrm{n}=31)$ mutations. The control group was selected from BC patients without mutations $(n=392)$. The $B R C A$-associated cancer cases were significantly more often triple negative compared with sporadic cancer (62\% vs. $14 \%$; $\mathrm{P}=0.0001$ ). Luminal B HER2-positive and HER2-positive non-luminal subtypes were observed more often in the control group (33 and 17\%). The luminal A subtype was detected in $53 \%$ of $C H E K 2$ mutation carriers and $45 \%$ of $N O D 2$ mutation carriers. A lower histological grade was observed significantly more often in patients with $C H E K 2$ mutations in comparison with the control group ( 88 vs. $69 \%$; $\mathrm{P}=0.003$ ). Lymph nodes without metastases were reported more frequently in NOD2 mutation carriers ( 74 vs. $54 \%$; $\mathrm{P}=0.038$ ), in $B R C A 1$ mutations (73 vs. 54\%; $\mathrm{P}=0.004$ ) and, although not significantly, in CHEK2 mutation carriers (69 vs. $54 \% ; \mathrm{P}=0.071$ ) compared with the control group. In conclusion, BRCA1 mutation was associated with TNBC and the luminal B HER2 (-) subtype. HER2-positive subtypes were characteristic of the control group. CHEK2 and NOD2 mutation carriers had a more favorable profile of prognostic factors.
\end{abstract}

\footnotetext{
Correspondence to: Dr Joanna Huszno, I Radiation and Clinical Oncology Department, Maria Skłodowska-Curie Memorial Cancer Center and Institute of Oncology, 15 Wybrzeze Armii Krajowej Street, 44-101 Gliwice, Poland

E-mail: joahus@wp.pl
}

Key words: breast cancer, BRCA gene mutation, CHEK2 gene mutation, NOD2 gene mutation, clinicopathological factors

\section{Introduction}

Breast cancer is a heterogeneous complex of diseases, comprising a spectrum of numerous subtypes with distinct biological features. These biological subtypes lead to differences in treatment responses and clinical outcomes (1). Traditional classification systems include biological characteristics, including tumor size, lymph node involvement, histological grade, patient age, estrogen receptors (ER), progesterone receptors (PR) and human epidermal growth factor receptor 2 (HER2 or c-erbB2) status (2). The diagnosis of breast cancer is based on clinical examination in combination with imaging and is confirmed by pathological assessment. Clinical examination includes bimanual palpation of the breasts and locoregional lymph nodes. Imaging diagnostics facilitate the assessment of the presence of distant metastases (bones, liver and lungs). A neurological examination is only required when symptoms are present (3).

The pathological report should include the histological type, grade, immunohistochemical (IHC) evaluation of estrogen receptor (ER) status (using a standardized assessment methodology, e.g., Allred or H-score), and progesterone receptor (PR) and human epidermal growth factor 2 receptor (HER2) gene expression. HER2 gene amplification status may be determined directly from all invasive tumors using in situ hybridization (fluorescent, chromogenic or silver), either as a replacement for IHC or for tumors with an ambiguous (2+) IHC score (4). Proliferation markers such as Ki67 should also be assessed (5).

Breast cancer tumors are divided into subtypes according to aforementioned factors, defined by routine histology and IHC (the 2015 St Gallen Consensus Conference). This classification is very important for prognosis and treatment decisions $(1,6)$. Luminal-A is the most common subtype and represents 50-60\% of all breast cancer cases. This subtype is defined as ER-positive and/or PR-positive tumors with a negative HER2 and low Ki67 (proliferating cell nuclear antigen) index, assessed by immunohistochemistry. Patients with luminal-A breast cancer have a good prognosis and the relapse rate is significantly lower compared with that for other subtypes (7). Luminal-B tumors comprise $15-20 \%$ of breast cancer cases and have a more aggressive phenotype, higher histological grade, increased proliferative index and a worse prognosis. There are distinct HER2-negative (ER-positive; HER2-negative; Ki67\% high; PR low) and HER2-positive (ER-positive; HER2-positive; any Ki67; any PR) 
luminal B subtypes. HER2-positive cancer accounts for $15-20 \%$ of breast cancer subtypes. These tumors are characterized by high expression of the HER2 gene and other genes associated with the HER2 pathway and/or HER2 amplicon located on the 17q12 chromosome (8). The HER2-positive non-luminal subtype is highly proliferative, with negative steroid receptor status. The other group are basal-like tumors (triple negative, HER2-negative, ER and PR absent) (9). The progress in genetic diagnostics has led to the identification of novel molecular factors, including the BRCA1/2, CHEK2, TP53 and PALB2 genes (10-13). Additionally, the role of tumor-infiltrating lymphocytes (TILs) in carcinogenesis and cancer progression has been confirmed $(14,15)$. The development of novel specific molecular targets within cancer cells is currently an important goal of oncology and part of treatment individualization. In recent years there has been a significant increase in the influence of genetic factors on the diagnostic process and the therapeutic decisions of patients with cancer, particularly breast cancer.

The purpose of the present study was to evaluate the correlation between molecular factors, including BRCA1, CHEK2 and NOD2 gene mutations, and well known clinicopathological factors in patients with breast cancer. As a follow-up study, it sought to assess the usefulness of molecular factors in the traditional classification systems of breast cancer.

\section{Patients and methods}

Patients. The present study retrospectively analyzed a data from a previous study conducted between the years 2007 and 2016 in the MSC Memorial Cancer Centre and Institute of Oncology, Gliwice Branch (COI; Poland), clinicopathological prognostic factors were analyzed in patients with breast cancer with confirmed BRCAl $(\mathrm{n}=73), C H E K 2(\mathrm{n}=51)$ and NOD2 $(n=31)$ mutations. The control group was selected from breast cancer patients without mutations $(\mathrm{n}=392)$. The patients in all groups (BRCA1, CHEK2 and NOD2 mutation carriers, and the control group) were treated according to the same protocol. All patients provided written informed consent allowing their biological material to be used to clinical research.

All patients were women diagnosed, treated and followed-up at the COI in Gliwice. Patient underwent clinical follow-up examinations every 3 months in the first 2 years, every 6 months thereafter until the 5 th year following diagnosis, and every year subsequently. Inclusion criteria were as follows: Breast cancer confirmed by microscopic examination; performance status ZUBROD 0-1; age >18 years; and normal values of renal and liver function, bone marrow. Data for age at onset, menopausal status, surgical procedures, disease stage according to TNM classification (T-the size of the tumor; N-spread of cancer to nearby lymph nodes; and M-metastasis), histology, estrogen and progesterone receptor status, HER2 status and contralateral breast cancer were gathered from hospital records and pathology reports. The analysis of patient medical records was performed according to national legal regulation. The complete characteristics of patients with regard to demographic and clinicopathological features are presented in Tables I and II. Treatment strategies are illustrated in Table III. Preliminary results of this study for $B R C A, C H E K 2$ and NOD2 mutations have been presented in our previous publications (16-18).
Methods. The status of $C H E K 2 * 1100$ delC and I157T mutations (GenBank NM_007194.3) was assessed by ASA-PCR and RFLP-PCR techniques, respectively. The present study examined the most common mutations in BRCA1 (c.68_69delAG, c.181T>G, c.4034delA, c.5266dupC and c.3700_3704del5; GenBank NM_007294.3) and BRCA2 (c.5946delT and c.9403delC; GenBank NM_000059.3) present in the Silesian population. The presence of thec.3016_3017insC mutation of NOD2 (GenBank NM_022162.1) was also evaluated in the study group (Table IV). Each patient provided informed consent prior to venous blood collection for a genetic test. Genomic DNA was isolated from peripheral blood leucocytes.

Statistical analysis. Statistical analysis was performed using STATISTICA 13 software (StatSoft, Inc., Tulsa, OK, USA). The frequency of side effects was counted. The qualitative features are presented as the percentage of their occurrence and were evaluated with Fisher's test and $\chi^{2}$ test with the Yates correction. $\mathrm{P}<0.05$ was considered to indicate a statistically significant difference.

\section{Results}

Clinical factors and mutations. BRCA1 mutation carriers were significantly younger in comparison with patients without detected mutations $(\mathrm{P}=0.0001)$. The median age of $B R C A 1$ mutation carriers was 43 years (range, 25-74 years) and for the control group it was 53 years (range, 26-78 years). Patients with $B R C A$-associated breast cancer were also significantly more often in the premenopausal age range compared with the control group (71 vs. $49 \%$; $\mathrm{P}=0.0005$ ). The median age at menarche was 14 years old, which was similar in the two groups $(\mathrm{P}=0.559)$. However, the median number of births was significantly lower in patients with BRCAl mutations $(\mathrm{P}=0.0001)$. The median age of $C H E K 2$ carriers was 50 years (range, 26-71). In the present analysis, $C H E K 2$ carriers were younger, although not significantly, compared with the control group ( $\mathrm{P}=0.081)$. No significant differences were identified between $C H E K 2$ mutation carriers and the control group according to postmenopausal status (47 vs. $51 \%$; $\mathrm{P}=0.656$ ). The median age at breast cancer diagnosis for the carriers of the NOD2 mutation was 47 years (range, 27-68). All mutation carriers were younger compared with patients in the control group. The youngest patients were $B R C A l$ mutation carriers (median age, 43 years), followed by those with the NOD2 mutation (median age, 47 years) and those with the CHEK2 mutation (median age, 50 years) (Table I). There were no differences in age between BRCA1 and NOD2 mutation carriers $(\mathrm{P}=0.338)$ or between patients with $C H E K 2$ and NOD2 mutations $(\mathrm{P}=0.268)$. BRCA1 mutation carriers were younger in comparison with patients with $C H E K 2$ mutation $(\mathrm{P}=0.015) . B R C A 1$ mutation carriers were more frequently in the premenopausal period compared with patients with the CHEK2 $(\mathrm{P}=0.037)$ or NOD2 mutation $(\mathrm{P}=0.054)$.

A history of cancer in the family was reported in 123 $(31 \%)$ in control group and $80(52 \%)$ patients with mutations $(\mathrm{P}=0.0001)$. A family history of cancer was observed more frequently in CHEK2 mutation carriers (61 vs. $31 \%$; $\mathrm{P}=0.0001$ ) and NOD2 mutation carriers (58 vs. $31 \%$; $\mathrm{P}=0.005)$ compared with control group patients. There was a detected tendency 
Table I. Clinicopathological characteristics of the patient according to mutation.

\begin{tabular}{|c|c|c|c|c|c|c|c|}
\hline Clincopathological criteria & $\begin{array}{c}B R C A 1 \\
\mathrm{n}=73\end{array}$ & $\begin{array}{c}\text { P-value } \\
\text { (BRCAl vs. } \\
\text { Control } \\
\text { group) }\end{array}$ & $\begin{array}{c}\text { CHEK2 } \\
\mathrm{n}=52\end{array}$ & $\begin{array}{c}\text { P-value } \\
\text { (CHEK2 vs. } \\
\text { Control } \\
\text { group) }\end{array}$ & $\begin{array}{c}\text { NOD2 } \\
\mathrm{n}=31\end{array}$ & $\begin{array}{c}\text { P-value } \\
\text { (NOD2 vs. } \\
\text { Control } \\
\text { group) }\end{array}$ & $\begin{array}{l}\text { Control } \\
\text { group, } \\
n=392\end{array}$ \\
\hline Age (median 52 years) & $43(24-74)$ & 0.0001 & $50(26-71)$ & 0.081 & $47(27-68)$ & 0.005 & $53(26-78)$ \\
\hline Menopausal status & & 0.0005 & & 0.656 & & 0.853 & \\
\hline Postmenopausal & $21(29 \%)$ & & $24(47 \%)$ & & $15(48 \%)$ & & $200(51 \%)$ \\
\hline Premenopausal & $52(71 \%)$ & & $27(53 \%)$ & & $16(52 \%)$ & & $192(49 \%)$ \\
\hline Cardiovascular diseases & & 1.00 & & 0.513 & & 0.681 & \\
\hline Yes & $4(5 \%)$ & & $4(8 \%)$ & & $2(6 \%)$ & & $21(5 \%)$ \\
\hline No & $69(95 \%)$ & & $47(92 \%)$ & & $29(94 \%)$ & & $371(95 \%)$ \\
\hline Infectious diseases & & 1.00 & & 0.412 & & 0.302 & \\
\hline Yes & $2(3 \%)$ & & $3(6 \%)$ & & $2(6 \%)$ & & $13(3 \%)$ \\
\hline No & $71(97 \%)$ & & $48(94 \%)$ & & $29(94 \%)$ & & $379(97 \%)$ \\
\hline Diabetes & & 0.661 & & 0.605 & & 0.499 & \\
\hline Yes & $2(3 \%)$ & & $0(0 \%)$ & & $1(3 \%)$ & & $8(2 \%)$ \\
\hline No & $71(97 \%)$ & & $51(100 \%)$ & & $30(97 \%)$ & & $384(98 \%)$ \\
\hline Hypertension & & 0.159 & & 0.116 & & 0.620 & \\
\hline Yes & $7(10 \%)$ & & $13(25 \%)$ & & $6(19 \%)$ & & $64(16 \%)$ \\
\hline No & $66(90 \%)$ & & $38(75 \%)$ & & $25(81 \%)$ & & $328(84 \%)$ \\
\hline \multicolumn{8}{|l|}{ History of cancer in family } \\
\hline Cancer & $31(42 \%)$ & 0.065 & $31(61 \%)$ & 0.0001 & $18(58 \%)$ & 0.005 & $123(31 \%)$ \\
\hline Breast cancer & $18(25 \%)$ & 0.0009 & $14(27 \%)$ & 0.001 & $11(35 \%)$ & 0.0003 & $39(10 \%)$ \\
\hline Colorectal cancer & $1(1 \%)$ & 0.336 & $7(14 \%)$ & 0.017 & $3(10 \%)$ & 0.193 & $18(5 \%)$ \\
\hline Gastric cancer & $3(4 \%)$ & 0.726 & $5(10 \%)$ & 0.044 & $2(6 \%)$ & 0.302 & $13(3 \%)$ \\
\hline Lung cancer & $5(7 \%)$ & 0.579 & $4(8 \%)$ & 0.505 & $1(3 \%)$ & 1.00 & $20(5 \%)$ \\
\hline Larynx cancer & $1(1 \%)$ & 1.00 & $3(6 \%)$ & 0.096 & $0(0 \%)$ & 1.00 & $7(2 \%)$ \\
\hline CNS & $1(1 \%)$ & 1.00 & $4(8 \%)$ & 0.013 & $0(0 \%)$ & 1.00 & $5(1 \%)$ \\
\hline
\end{tabular}

$B R C A 1$, BRCA1 DNA repair associated; $C H E K 2$, checkpoint kinase 2; NOD2, nucleotide binding oligomerization domain containing 2; CNS, central nervous system.

towards a family history of cancer in patients with $B R C A I$ mutations (42 vs. $31 \%$; $\mathrm{P}=0.065$ ). A family history of breast cancer was reported in patients with mutations in BRCA1 (25 vs. $10 \%$; $\mathrm{P}=0.0009), C H E K 2$ (27 vs. $10 \% ; \mathrm{P}=0.001)$ or NOD2 (35 vs. $10 \% ; \mathrm{P}=0.0003$ ) in comparison with the control group. Colorectal cancer (14 vs. $5 \%$; $\mathrm{P}=0.017)$ and gastric cancer $(10$ vs. $3 \% ; \mathrm{P}=0.044$ ) within the family history were observed more frequently in patients with $C H E K 2$ mutation compared with the control group. Similarly, a significant family history of CNS tumors was identified in patients with CHEK2 mutations (8 vs. $1 \% ; \mathrm{P}=0.013$ ) (Table I). There was reported no association between other types of cancer in family history and BRCAl, CHEK2 or NOD2 mutations.

Histopathological factors and mutations. Clinicopathological analysis was conducted. BRCAl-associated cancer had significantly more frequent negative steroid receptor status compared with the control group (62 vs. $31 \%$; $\mathrm{P}=0.0001$ ). HER 2 overexpression was significantly more frequently detected in women without mutations compared with BRCAl carriers (51 vs. 7\%;
$\mathrm{P}=0.0001$; Table II, Fig. 1). Histological type G3 was detected more frequently in patients with BRCAl mutations (55 vs. $31 \%$; $\mathrm{P}=0.0001$; Fig. 2). There were observed differences between two of the analyzed groups (CHEK2 carriers and the control group) with respect to ER-positive status (82 vs. 66\%; $\mathrm{P}=0.001$ ), PR-positive status (78 vs. 59\%; $\mathrm{P}=0.009)$ and HER2 overexpression ( 18 vs. $51 \%$; $\mathrm{P}=0.0001$; Table II, Figs. 1,3 and 4 ). The histological grade of breast cancer differed between patients with CHEK2 mutations and the control group (12\% G3 vs. $31 \% \mathrm{G} 3$; $\mathrm{P}=0.003$; Table II, Fig. 2). The absence of HER2 overexpression was observed significantly more frequently in NOD2 mutation carriers (90 vs. $49 \%$; $\mathrm{P}=0.0001$ ) compared with the control group (Table II, Fig. 1). By contrast, there were no differences between NOD2 mutation carriers and the control group with respect to ER ( 29 vs. $34 \%$; $\mathrm{P}=0.253$ ) and $\mathrm{PR}(32$ vs. $41 \%$; $\mathrm{P}=0.447)$ negative steroid receptor status (Table II, Figs. 3 and 4). A lower histological grade, G1-G2, was observed with similar frequency in NOD2 mutation carriers and the control group (74 vs. 69\%; $\mathrm{P}=0.687$; Table II, Fig. 2). G3 tumors were detected in $26 \%$ of mutation carriers and $31 \%$ of subjects in the control group. 
Table II. Pathological characteristics of the patients.

\begin{tabular}{|c|c|c|c|c|c|c|c|}
\hline Pathological features & $\begin{array}{c}B R C A 1, \\
\mathrm{n}=73(\%)\end{array}$ & $\begin{array}{c}\text { P-value } \\
\text { (BRCAl vs. } \\
\text { Control } \\
\text { group) }\end{array}$ & $\begin{array}{c}\text { CHEK2, } \\
\mathrm{n}=51(\%)\end{array}$ & $\begin{array}{c}\text { P-value } \\
\text { (CHEK2 vs. } \\
\text { Control } \\
\text { group) }\end{array}$ & $\begin{array}{c}N O D 2, \\
\mathrm{n}=31(\%)\end{array}$ & $\begin{array}{c}\text { P-value } \\
\text { (NOD2 vs. } \\
\text { Control } \\
\text { group) }\end{array}$ & $\begin{array}{c}\text { Control } \\
\text { group, } \\
\mathrm{n}=392(\%)\end{array}$ \\
\hline HER 2 overexpression & & 0.0001 & & 0.0001 & & 0.0001 & \\
\hline Positive & $5(7)$ & & $9(18)$ & & $3(10)$ & & $199(51)$ \\
\hline Negative & $68(93)$ & & $42(82)$ & & $28(90)$ & & $193(49)$ \\
\hline Tumor grade & & 0.0001 & & 0.003 & & 0.687 & \\
\hline G1-G2 & $33(45)$ & & $45(88)$ & & $23(74)$ & & $269(69)$ \\
\hline G3 & $40(55)$ & & $6(12)$ & & $8(26)$ & & $123(31)$ \\
\hline Estrogen status & & 0.0001 & & 0.001 & & 0.253 & \\
\hline Positive & $25(34)$ & & $42(82)$ & & $22(71)$ & & $258(66)$ \\
\hline Negative & $48(66)$ & & $9(18)$ & & $9(29)$ & & $134(34)$ \\
\hline Progesterone status & & 0.0001 & & 0.009 & & 0.447 & \\
\hline Positive & $21(29)$ & & $40(78)$ & & $21(68)$ & & $231(59)$ \\
\hline Negative & $52(71)$ & & $11(22)$ & & $10(32)$ & & $161(41)$ \\
\hline Clinical staging nodes & & 0.004 & & 0.071 & & 0.038 & \\
\hline Positive & $20(27)$ & & $16(31)$ & & $8(26)$ & & $179(46)$ \\
\hline Negative & $53(73)$ & & $35(69)$ & & $23(74)$ & & $213(54)$ \\
\hline Tumor size & & 0.002 & & 0.186 & & 0.327 & \\
\hline $\mathrm{T} 1-\mathrm{T} 2$ & $48(66)$ & & $38(75)$ & & $28(90)$ & & $322(82)$ \\
\hline T3-T4 & $25(34)$ & & $13(25)$ & & $3(10)$ & & $70(18)$ \\
\hline Clinical staging & & 0.484 & & 0.253 & & 0.142 & \\
\hline I & $12(16)$ & & $16(31)$ & & $12(39)$ & & $87(22)$ \\
\hline II & $46(63)$ & & $23(45)$ & & $14(45)$ & & $221(56)$ \\
\hline III & $15(21)$ & & $12(24)$ & & $5(16)$ & & $84(21)$ \\
\hline Histological type & & 0.018 & & 0.033 & & 0.252 & \\
\hline Ductal invasive carcinoma & $56(77)$ & & $32(63)$ & & $27(87)$ & & $301(77)$ \\
\hline Lobular invasive carcinoma & $1(1)$ & & $11(22)$ & & $3(10)$ & & $38(10)$ \\
\hline Other & $16(22)$ & & $8(16)$ & & $1(3)$ & & $53(14)$ \\
\hline
\end{tabular}

$B R C A 1$, BRCA1 DNA repair associated; $C H E K 2$, checkpoint kinase 2; NOD2, nucleotide binding oligomerization domain containing 2; HER2, human epidermal growth factor receptor 2.

Lymph nodes metastases occurred more frequently in the control group of patients compared with the group with BRCAl mutations (46 vs. $27 \% ; \mathrm{P}=0.004$ ). There was an observed tendency towards the presence of lymph node metastases in patients of the control group compared with CHEK2 mutation carriers (46 vs. $31 \%$; $\mathrm{P}=0.071$ ). Lymph nodes without metastases (N0) were reported more frequently in patients with NOD2 mutations compared with the control group (74\% vs. 54\%; P=0.038) (Table II, Fig. 5).

In the present study, patients with $B R C A 1$ mutations had significantly more frequent large tumor sizes (T3-T4) compared with the control group (34 vs. $18 \%$; $\mathrm{P}=0.002$ ). CHEK2 mutation carriers were slightly more likely to present with locally advanced breast cancer (T3-T4) compared with the control group ( 25 vs. $18 \%$; $\mathrm{P}=0.186$ ) and patients with NOD2 mutations exhibited no differences in T grade (Table II, Fig. 6).

The majority of patients in studied groups had the ductal invasive carcinoma subtype: $77 \%$ of $B R C A l$ mutation carriers, $63 \%$ of
CHEK2 mutation carriers and $87 \%$ of patients with NOD2 mutations. The lobular type of breast cancer was detected significantly more frequently in CHEK2 mutation carriers compared with the control group (22 vs. 10\%; $\mathrm{P}=0.033$ ) (Table II).

Compared with the control group, BRCAl mutation carriers were younger, and more frequently had higher tumor sizes (T3-T4), G3 tumors, negative steroid receptor status (ER-) and tumors without HER2 overexpression. CHEK2 mutation carriers more frequently had tumors without HER2 overexpression, ER-positive receptor status and lower histological grade (G1-G2). Patients with NOD2 mutation were younger and frequently had tumors without HER2 overexpression, when compared with the control group.

Molecular subtypes of breast cancer in patients with mutations. The distributions of the molecular types in breast cancer patients with the BRCA1, CHEK2 and NOD2 mutations differed significantly from the distributions of the subtypes in 
Table III. Treatment strategy according to the presence of mutation.

\begin{tabular}{lcccc} 
Treatment strategy & BRCAl, $\mathrm{n}=76(\%)$ & CHEK2, $\mathrm{n}=51(\%)$ & NOD2, $\mathrm{n}=31$ & $\begin{array}{c}\text { Control group, } \\
\mathrm{n}=392(\%)\end{array}$ \\
\hline Chemotherapy regimen & & & & \\
ACFFC & $48(66)$ & $22(44)$ & $12(40)$ & $328(84)$ \\
AC + taxanes & $18(25)$ & $8(16)$ & $5(17)$ & $41(10)$ \\
CMF & $5(7)$ & $2(4)$ & $1(3)$ & $3(1)$ \\
Without & $0(0)$ & $18(35)$ & $12(39)$ & $20(5)$ \\
Trastuzumab therapy & $1(1)$ & $8(16)$ & $2(6)$ & $179(46)$ \\
Yes & $72(99)$ & $43(84)$ & $29(94)$ & $213(54)$ \\
No & & & & \\
Hormonotherapy & $28(38)$ & $44(86)$ & $22(71)$ & $255(65)$ \\
Yes & $45(62)$ & $7(14)$ & $9(29)$ & $137(35)$ \\
No & & & & \\
Local treatment & $51(70)$ & $35(69)$ & $17(55)$ & $264(67)$ \\
Mastectomy & $14(19)$ & $15(29)$ & $14(45)$ & $106(27)$ \\
Breast conservation surgery (BCT) & $8(11)$ & $1(2)$ & $0(0)$ & $22(6)$ \\
Without surgery & & & & \\
Radiotherapy & $51(70)$ & $27(53)$ & $24(77)$ & $282(72)$ \\
Yes & $22(30)$ & $24(47)$ & $7(23)$ & $110(28)$ \\
No &
\end{tabular}

BRCA1, BRCA1 DNA repair associated; $C H E K 2$, checkpoint kinase 2; NOD2, nucleotide binding oligomerization domain containing 2; AC, anthracycline and cyclophosphamide; FAC, 5-Fluorouracil, anthracycline and cyclophosphamide; CMF, cyclophosphamide, mitoxantrone, 5-Fluorouracil; BCT, breast conserving therapy.

Table IV. Mutation sites of all analyzed molecular factors.

\begin{tabular}{lrr}
\hline Mutation sites & $\mathrm{n}$ & $\%$ \\
\hline CHEK2 & 51 & \\
c.470T>C & 48 & 94 \\
c.1100delC & 3 & 6 \\
NOD2 & 31 & \\
c.3016_3017insC & 31 & 100 \\
BRCA1 & 73 & \\
c.5266dupC & 41 & 36 \\
c.181T>G & 25 & 3 \\
c.68_69delAG & 2 & 1 \\
c.3700_3704delGTAAA & 2 & 1 \\
c.1692_1693delTG & 1 & 1 \\
c.213-12A $>$ G & 1 & 3 \\
c.5346G $>$ A & 1 & \\
\hline
\end{tabular}

BRCA1, BRCA1 DNA repair associated; CHEK2, checkpoint kinase 2; NOD2, nucleotide binding oligomerization domain containing 2 .

the control group (Table V, Fig. 7). The BRCAl-associated cancers were significantly more often triple negative (TNBC) compared with the tumors in the sporadic cancer cases (62 vs. 14\%; $\mathrm{P}=0.0001)$. Luminal B subtypes, particularly Luminal

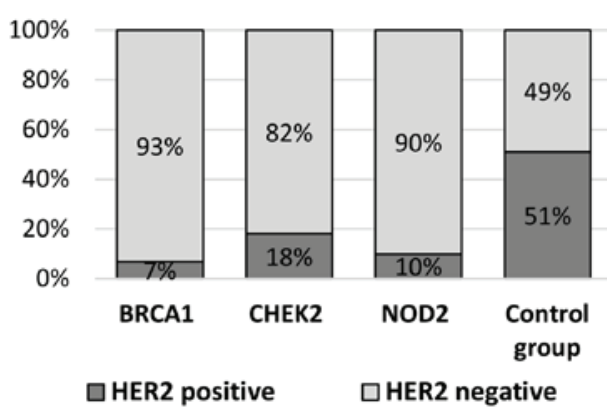

Figure 1. Correlation between molecular factors and HER2 overexpression. HER2, human epidermal growth factor receptor 2; BRCA1, BRCA1 DNA repair associated; $C H E K 2$, checkpoint kinase 2; NOD2, nucleotide binding oligomerization domain containing 2 .

B HER2-positive subtypes, were reported more frequently in the control group (56 and 33\%, respectively) in comparison with the mutation carriers: BRCAl (34 and 7\%, respectively); CHEK2 (33 and 12\%, respectively) and NOD2 (26 and 6\%, respectively). Luminal A type breast cancer was diagnosed more frequently in CHEK2 mutation carriers (53\%) and NOD2 mutation carriers $(45 \%)$ compared with the control group (13\%) (Table V).

\section{Discussion}

In previous studies, patients with $B R C A 1$ mutation were characterized by their younger age, negative steroid receptor status 


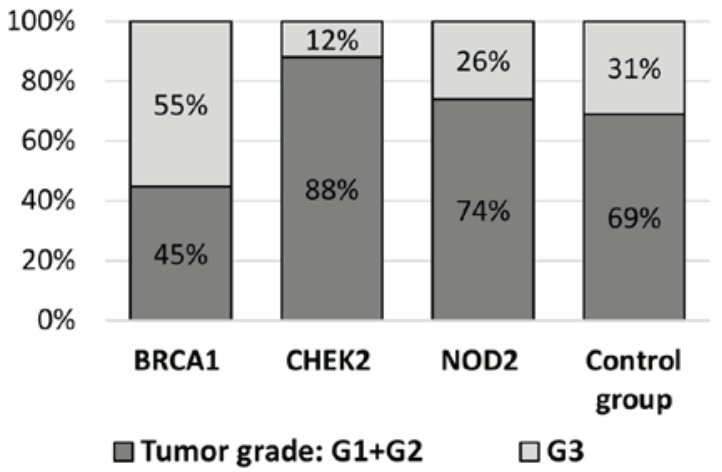

Figure 2. Correlation between molecular factors and tumor grade. BRCA1, BRCA1 DNA repair associated; CHEK2, checkpoint kinase 2; NOD2, nucleotide binding oligomerization domain containing 2 .

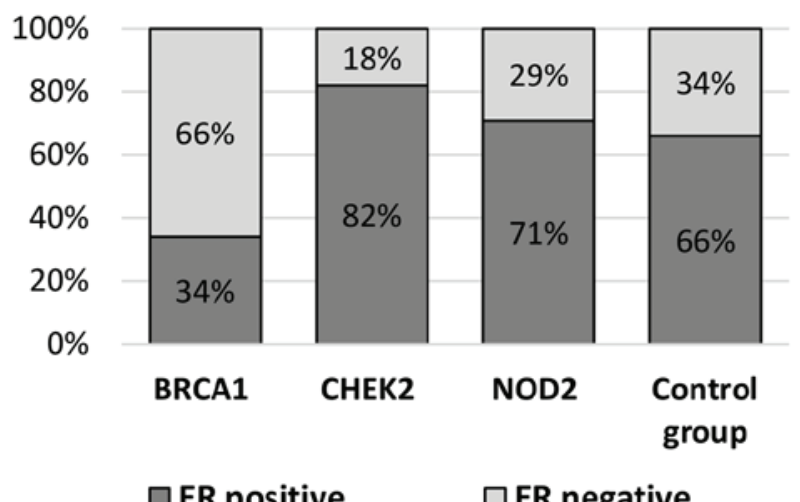

Figure 3. Correlation between molecular factors and ER status. ER, estrogen receptor; $B R C A 1$, BRCA1 DNA repair associated; $C H E K 2$, checkpoint kinase 2; NOD2, nucleotide binding oligomerization domain containing 2.

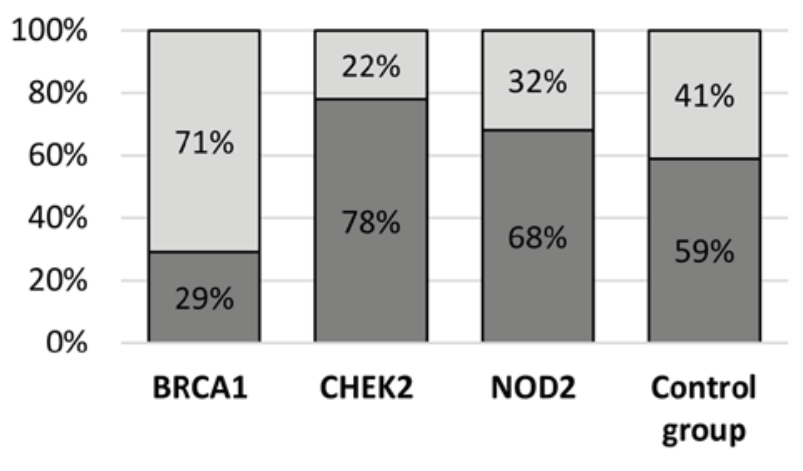

Figure 4. Correlation between molecular factors and PR status. PR, progesterone receptor; $B R C A 1$, BRCA1 DNA repair associated; $C H E K 2$, checkpoint kinase 2; NOD2, nucleotide binding oligomerization domain containing 2.

(ER-), HER2 negative and triple negative tumors (19). The basal type of cancer was also significantly associated with $B R C A 1$ expression (20). The present results confirmed those of previous studies. In the analyzed group, the median age of patients with BRCA1 mutations was significantly lower compared with that of patients in the control group (43 vs. 53 years; $\mathrm{P}<0.0001$ ). These mutation carriers were also more frequently in the premenopausal period ( 71 vs. $49 \%$; $\mathrm{P}=0.0005$ ), had more locally

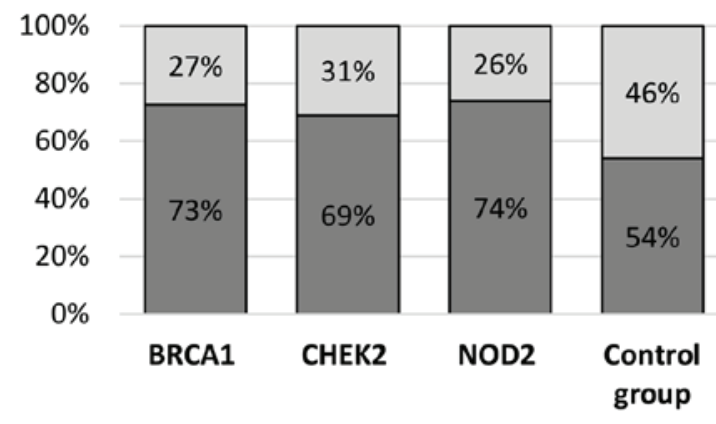

$\square$ Node status: negative $\quad \square$ positive

Figure 5. Correlation between molecular factors and node status. $B R C A 1$, BRCA1 DNA repair associated; CHEK2, checkpoint kinase 2; NOD2, nucleotide binding oligomerization domain containing 2 .

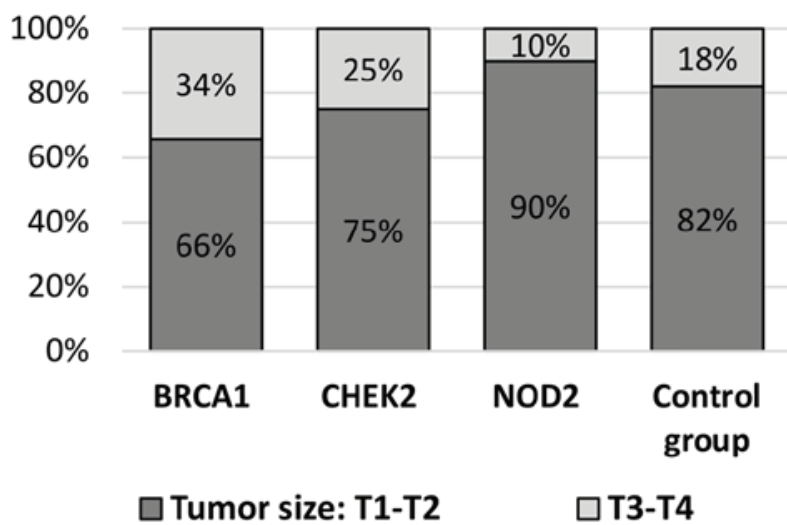

Figure 6. Correlation between molecular factors and tumor size. BRCA1, BRCA1 DNA repair associated; $C H E K 2$, checkpoint kinase 2; NOD2, nucleotide binding oligomerization domain containing 2 .

advanced primary tumors ( 34 vs. $18 \%$; $\mathrm{P}=0.002$ ) and were more often triple negative ( 62 vs. $14 \%$; $\mathrm{P}=0.0001)$. The more advanced disease stage and TNBC subtype in BRCA1 mutation carriers may be associated with a more aggressive clinicopathological tumor type. These observations are consistent with those from previous studies (21-24).

A study conducted by de Bock et al (25) demonstrated that patients with a $C H E K 2$ mutation were significantly younger than patients without this mutation (49.0 vs. 53.2 years; $\mathrm{P}=0.03$ ). Patients with a germline CHEK2*1100delC mutation more frequently had tumors with positive steroid receptor status [ER (91 vs. $69 \%$; $\mathrm{P}=0.03$ ); $\mathrm{PR}$ (81 vs. $53 \% ; \mathrm{P}=0.04$ )] in comparison with non-carriers. By contrast, no significant differences between these two groups were reported with respect to tumor size, histological subtype, grade, or surgical procedure, or in the choice of adjuvant systemic therapy or radiotherapy (25). In patients with early-onset breast cancer from Poland, ER-positive status was observed more frequently in carriers of CHEK2 truncating mutations compared with non-carriers (72 vs. $58 \%$; $\mathrm{P}=0.01)$. Women with a $C H E K 2$ mutation had a fourfold increased risk of ER-positive breast cancer in the Polish population (26). A correlation between CHEK2*1100delC mutation status and tumor characteristics was also reported in trial conducted by Kilpivaara et al (27). In that study, no association was observed between this mutation and hormone 
Table V. Molecular subtype of breast cancer according to St Gallen.

\begin{tabular}{|c|c|c|c|c|c|c|c|}
\hline Molecular subtype & $\begin{array}{c}B R C A 1, \\
\mathrm{n}=76(\%)\end{array}$ & $\begin{array}{l}\text { P-value } \\
B R C A l \text { vs. } \\
\text { Control } \\
\text { group }\end{array}$ & $\begin{array}{c}\text { CHEK2, } \\
\mathrm{n}=51(\%)\end{array}$ & $\begin{array}{l}\text { P-value, } \\
C H E K 2 \text { vs. } \\
\text { Control } \\
\text { group }\end{array}$ & $\begin{array}{c}\text { NOD2, } \\
\mathrm{n}=31(\%)\end{array}$ & $\begin{array}{l}\text { P-value } \\
\text { NOD2 vs. } \\
\text { Control } \\
\text { group }\end{array}$ & $\begin{array}{c}\text { Control } \\
\text { group, } \\
\mathrm{n}=392(\%)\end{array}$ \\
\hline Luminal A & $3(4)$ & & $27(53)$ & & $14(45)$ & & $49(13)$ \\
\hline Luminal B HER2 negative & $20(27)$ & & $11(22)$ & & $6(19)$ & & $90(23)$ \\
\hline Luminal B HER2 positive & $5(7)$ & 0.0001 & $6(12)$ & 0.0001 & $2(6)$ & 0.0001 & $131(33)$ \\
\hline HER 2 positive non luminal & $0(0)$ & & $3(6)$ & & $1(3)$ & & $68(17)$ \\
\hline Triple negative & $45(62)$ & & $4(8)$ & & $8(26)$ & & $54(14)$ \\
\hline
\end{tabular}

BRCA1, BRCA1 DNA repair associated; CHEK2, checkpoint kinase 2; NOD2, nucleotide binding oligomerization domain containing 2; HER2, human epidermal growth factor receptor 2.

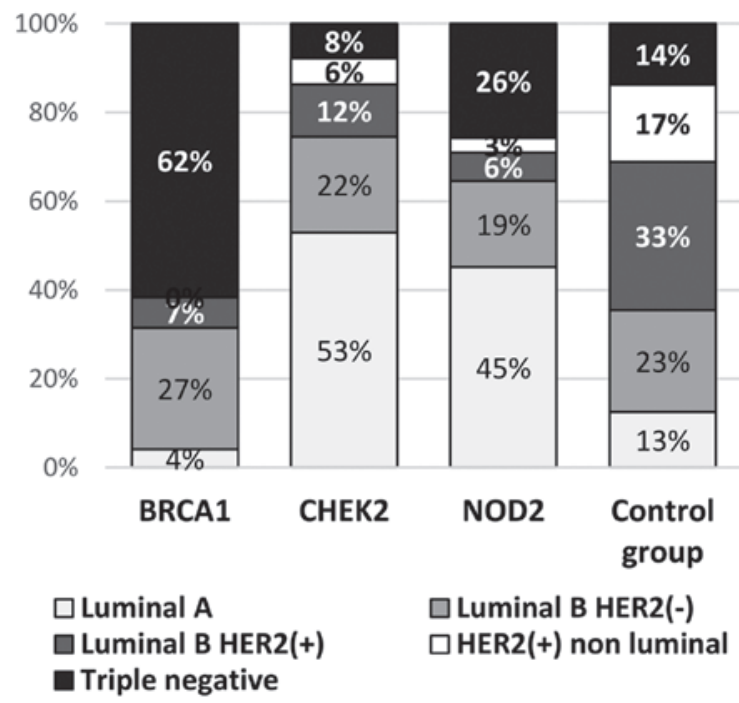

Figure 7. Correlation between molecular factors and molecular breast cancer type. BRCA1, BRCA1 DNA repair associated; $C H E K 2$, checkpoint kinase 2; $N O D 2$, nucleotide binding oligomerization domain containing 2 .

receptor status, tumor histology or lymph node status. Another analyzed risk factor was ionizing radiation treatment. In a study conducted by Broeks et al (28), an association was observed between BRCA1, BRCA2 and CHEK2 germline mutation carriers and the risk of radiation-induced contralateral breast cancer in comparison with non-carriers [odds ratio (OR), 2.51; 95\% confidence interval, 1.03-6.10; $\mathrm{P}=0.049]$. In the present analysis, the presence of luminal A type breast cancer was reported in CHEK2 mutation carriers more frequently than in the control group (53\% vs. $13 \%$; $\mathrm{P}=0.0001)$. HER 2 overexpression was detected more frequently in the control group. In the present study, there was observed tendency towards a family history of cancer in patients of the control group compared with mutation carriers ( 46 vs. $31 \%$; $\mathrm{P}=0.071$ ). The present study also observed a tendency towards a family history of cancer, particularly gastric, colorectal or CNS cancer, in the carrier groups. Breast cancer within the family history was observed significantly more often in $C H E K 2$ mutation carriers in comparison with the control group ( 27 vs. $10 \%$; $\mathrm{P}=0.001$ ). Lower histological grade was observed significantly more often in patients with $C H E K 2$ mutations compared with the control group ( 88 vs. $69 \%$; $\mathrm{P}=0.003$ ). The carriers also had locally advanced breast cancer (T3-T4) slightly more frequently than the control group ( 25 vs. $18 \% ; \mathrm{P}=0.186$ ). Domagala et al (29) reported a significant association between $C H E K 2$ mutations and molecular breast cancer subtype classification $(\mathrm{P}=0.004)$. Patients with mutations in the CHEK2 gene primarily had luminal subtypes of breast cancer $(108 / 117=92.3 \%)$. The CHEK2-I157T variant was associated with the luminal A subtype $(\mathrm{P}=0.01)$, whereas $C H E K 2$-truncating mutations were associated with the luminal $\mathrm{B}$ subtype $(\mathrm{P}=0.005)$.

In certain studies, there was an observed association between the NOD2 3020insC mutation and early breast cancer $(\mathrm{OR}=1.9 ; \mathrm{P}=0.01)$ (30). Similarly, ductal invasive carcinoma breast cancer with an in-situ component was more frequently reported in mutation carriers $(\mathrm{OR}=2.2 ; \mathrm{P}=0.006)(30)$. In the present group, all patients had early breast cancer. Ductal invasive carcinoma was also observed more frequently in NOD2 mutation carriers ( 87 vs. $77 \%$; $\mathrm{P}=0.252$ ) in comparison with the control group. Other clinicopathological factors were also analyzed. Janiszewska et al (31) did not report any NOD2 mutations in patients diagnosed with breast cancer after the age of 50 years. There was no reported association between NOD2 mutations and a strong family history of breast cancer. This mutation frequency $(11.4 \%)$ was two times higher in women from families with a single case of breast cancer. The association of NOD2 mutations with other common types of cancer, including digestive tract cancer, was described. The median age at breast cancer diagnosis in the present group of patients was 47 years (range, 26-68) for the carriers of the NOD2 mutation and 53 years (range, 26-78) for the control group. Differences were observed with respect to age between the two groups. The other factors associated with NOD2 mutations in the present study were: HER2 negative tumors (HER2-) and lymph nodes without metastases (N-). The most common type of breast cancer in this group was the Luminal type A and the TNBC subtype.

In conclusion, the presence of mutations was associated with a younger age of disease diagnosis, independent of mutation type (BRCA1, CHEK2 and NOD2). BRCA1 mutation was associated with TNBC cancer and the Luminal B HER2-negative breast cancer subtype, CHEK2 mutation with 
the Luminal A and Luminal B HER2-negative subtypes, and NOD2 mutation with Luminal A breast cancer and the TNBC subtype. CHEK2 and NOD2 mutation carriers had favorable prognostic profiles, such as G1-G2, N (-) and HER2-negative tumors.

\section{Acknowledgements}

Not applicable.

\section{Funding}

No funding was received.

\section{Availability of data and materials}

The datasets used and/or analyzed during this study are available from the corresponding author on reasonable request.

\section{Authors' contributions}

$\mathrm{JH}$ is responsible for the study design, preparation of the manuscript and final approval of the version to be published. ZK conducted the statistical analysis, corrected the manuscript, provided intellectual content and gave final approval of the version to be published.

\section{Ethics approval and consent to participate}

Not applicable. The present study was retrospective.

\section{Patient consent for publication}

Not applicable.

\section{Competing interests}

The authors declare that they have no competing interests.

\section{References}

1. Yersal O and Barutca S: Biological subtypes of breast cancer: Prognostic and therapeutic implications. World J Clin Oncol 10: 412-424, 2014.

2. Brierley JD, Gospodarowicz MK and Wittekind C: TNM Classification of Malignant Tumours. 8th ed. Oxford, UK: Wiley Blackwell, 2017.

3. Senkus E, Kyriakides S, Ohno S, Penault-Llorca F, Poortmans P, Rutgers E, Zackrisson $\mathrm{S}$ and Cardoso F; ESMO Guidelines Committee: Primary breast cancer: ESMO clinical practice guidelines. Ann Oncol 26 (Suppl 5): v8-v30, 2015.

4. Nadji M, Gomez-Fernandez C, Ganjei-Azar P and Morales AR: Immuno-histochemistry of estrogen and progesterone receptors reconsidered: Experience with 5,993 breast cancers. Am J Clin Pathol 123: 21-27, 2005

5. Ragab HM, Samy N, Afify M, Maksoud NA and Shaaban HM. Assessment of Ki-67 as a potential biomarker in patients with breast cancer. J Genet Engineering and Biotechnol 16: 479-484, 2018.

6. Gnant M, Thomssen C and Harbeck N: St. Gallen/Vienna 2015: A Brief summary of the consensus discussion. Breast Care (Basel) 10: 124-130, 2015.

7. Carey LA, Perou CM, Livasy CA, Dressler LG, Cowan D, Conway K, Karaca G, Troester MA, Tse CK, Edmiston S, et al: Race, breast cancer subtypes, and survival in the Carolina breast cancer study. JAMA 295: 2492-24502, 2006.
8. Creighton CJ: The molecular profile of luminal B breast cancer. Biologics 6: 289-297, 2012.

9. Hubalek M, Czech T and Müller H: Biological subtypes of triple-negative breast cancer. Breast Care (Basel) 12: 8-14, 2017.

10. Godet I and Gilkes DM: BRCA1 and BRCA2 mutations and treatment strategies for breast cancer. Integr Cancer Sci Ther 4 , 2017.

11. Apostolou P and Papasotiriou I: Current perspectives on CHEK2 mutations in breast cancer. Breast Cancer (Dove Med Press) 9: 331-335, 2017.

12. Silwal-Pandit L, Vollan HK, Chin SF, Rueda OM, McKinney S, Osako T, Quigley DA, Kristensen VN, Aparicio S, Børresen-Dale $\mathrm{AL}$, et al: TP53 mutation spectrum in breast cancer is subtype specific and has distinct prognostic relevance. Clin Cancer Res 20: 3570-3580, 2014.

13. Southey MC, Winship I and Nguyen-Dumont T: PALB2: Research reaching to clinical outcomes for women with breast cancer. Hered Cancer Clin Pract 14: 9, 2016.

14. Huszno J, Nożyńska EZ, Lange D, Kołosza Z and Nowara E: The association of tumor lymphocyte infiltration with clinicopathological factors and survival in breast cancer. Pol J Pathol 68: 26-32, 2017.

15. Montagna E, Vingiani A, Maisonneuve P, Cancello G, Contaldo F, Pruneri G and Colleoni M: Unfavorable prognostic role of tumor-infiltrating lymphocytes in hormone-receptor positive, HER 2 negative metastatic breast cancer treated with metronomic chemotherapy. Breast 34: 83-88, 2017.

16. Huszno J, Kołosza Z and Grzybowska E: BRCA1 mutation in breast cancer patients: Analysis of prognostic factors and survival. Oncol Lett 17: 1986-1995, 2019.

17. Huszno J, Budryk M, Kołosza Z, Tęcza K, Pamuła Piłat J, Nowara E and Grzybowska E: A comparison between CHEK2*1100delC/I157T mutation carrier and noncarrier breast cancer patients: A clinicopathological analysis. Oncology 90: 193-198, 2016.

18. Huszno J, Kołosza K, Tęcza T, Pamuła-Piłat J, Mazur M and Grzybowska E: Comparison between NOD2 gene mutation carriers (3020insC) and non-carriers in breast cancer patients: A clinicopathological and survival analysis. AMS Civilization Dis 3: $10 \mathrm{e}-15 \mathrm{e}, 2018$.

19. Triantafyllidou O, Vlachos IS, Apostolou P, Konstantopoulou I, Grivas A, Panopoulos C, Dimitrakakis C, Kassanos D, Loghis C, Bramis I, et al: Epidemiological and clinicopathological characteristics of BRCA-positive and BRCA-negative breast cancer patients in Greece. J BUON 20: 978-984, 2015.

20. Kutomi G, Ohmura T, Suzuki Y, Kameshima H, Shima H, Takamaru T, Satomi F, Otokozawa S, Mori M and Hirata K: Clinicopathological characteristics of basal type breast cancer in triple-negative breast cancer. J Cancer Therapy 3: 836-840, 2012 .

21. Evans DG, Lalloo F, Howell S, Verhoef S, Woodward ER and Howell A: Low prevalence of HER2 positivity amongst BRCA1 and BRCA2 mutation carriers and in primary BRCA screens. Breast Cancer Res Treat 155: 597-601, 2016.

22. Peshkin BN, Alabek ML and Isaacs C: BRCA1/2 mutations and triple negative breast cancers. Breast Dis 32: 25-33, 2010.

23. Huszno J, Budryk M, Kołosza $Z$ and Nowara $E$ : The influence of BRCA1/BRCA2 mutations on toxicity related to chemotherapy and radiotherapy in early breast cancer patients. Oncology 85: 278-82, 2013

24. Kirova YM, Savignoni A, Sigal-Zafrani B, de La Rochefordiere A, Salmon RJ, This P, Asselain B, Stoppa-Lyonnet D and Fourquet $\mathrm{A}$ : Is the breast conserving treatment with radiotherapy appropriate in BRCA1/2 mutation carries? Long-term results and review of the literature. Breast Cancer Res Treat 120: 119-126, 2010.

25. de Bock GH, Mourits MJ, Schutte M, Krol-Warmerdam EM, Seynaeve C, Blom J, Brekelmans CT, Meijers-Heijboer H, van Asperen CJ, Cornelisse CJ, et al: Association between the CHEK $2 * 1100$ delC germ line mutation and estrogen receptor status. Int J Gynecol Cancer 16: 552-555, 2006.

26. Cybulski C, Huzarski T, Byrski T, Gronwald J, Debniak T, Jakubowska A, Gorski B, Wokolorczyk D, Masojc B, Narod SA and Lubiński J: Estrogen receptor status in CHEK2-positive breast cancers: Implications for chemoprevention. Clin Genet 75: 72-78, 2009.

27. Kilpivaara O, Bartkova J, Eerola H, Syrjäkoski K, Vahteristo P, Lukas J, Blomqvist C, Holli K, Heikkilä P, Sauter G, et al: Correlation of CHEK2 protein expression and c.1100delC mutation status with tumor characteristics among unselected breast cancer patients. Int J Cancer 113: 575-580, 2005. 
28. Broeks A, Braaf LM, Huseinovic A, Nooijen A, Urbanus J, Hogervorst FB, Schmidt MK, Klijn JG, Russell NS, Van Leeuwen FE and Van 't Veer LJ: Identification of women with an increased risk of developing radiation-induced breast cancer: A case only study. Breast Cancer Res 9: R26, 2007.

29. Domagala D, Wokolorczyk D, Cybulski C, Huzarski T, Lubinski J and Domagala W: Different CHEK2 germline mutation are associated with distinct immunophenotyping molecular subtypes of breast cancer. Breast Cancer Res Treat 132: 937-945, 2011.
30. Huzarski T, Lener M, Domagala W, Gronwald J, Byrski T, Kurzawski G, Suchy J, Chosia M, Woyton J, Ucinski M, et al: The 3020insC allele of NOD2 predisposes to early-onset breast cancer. Breast Cancer Res Treat 89: 91-93, 2005.

31. Janiszewska H, Haus O, Lauda-Swieciak A, Bak A, Mierzwa T, Sir J and Laskowski R: The NOD2 3020insC mutation in women with breast cancer from the Bydgoszcz region in Poland. First results. Hered Cancer Clin Pract 4 : 15-19, 2006. 